\title{
O CONCEITO DE "VONTADE" NA ÉTICA DE ESPINOSA
}

\author{
Albertinho Luiz Gallina ${ }^{1}$ \\ Universidade Federal de Santa Maria (UFSM) \\ (D) https://orcid.org/0000-0002-0310-808X
}

\section{RESUMO:}

Neste artigo pretendo apresentar uma interpretação do sentido que Espinosa atribuiu ao conceito de "vontade". Mostrar como ele se afastou da concepção que a tradição tinha desse conceito, e qual é o papel que o mesmo desempenha nas deduções geométricas empregadas em suas demonstrações. Por fim, levando em consideração os dois primeiros livros da sua Ética, pretendo esclarecer em que medida o conceito de "vontade" tornou possível tanto a demonstração do conhecimento quanto da liberdade.

PALAVRAS-CHAVE: Vontade; Conhecimento; Liberdade.

\section{THE CONCEPT OF "WILL" IN SPINOZA'S ETHICS}

\begin{abstract}
:
Abstract: In this article I intend to present an interpretation of the sense that Spinoza ascribes to the concept of 'will', showing how he moved away from the concept that the tradition had this concept, and what is the role that it plays in geometric deductions used in their statements. Finally, taking into account the first two books of his Ethics, I want to clarify to what extent the concept of 'will' made it possible both the demonstration of knowledge and freedom.
\end{abstract}

KEY WORDS: Will; Knowledge; Freedom

Ao tratar a sua Ética em "more geométrico", Espinosa pensava que os conceitos envolvidos na ética também são entidades que precisam ser estudadas segundo a natureza que lhes é própria, segundo as suas propriedades e, finalmente, demonstrar de que modo cada propriedade decorre necessariamente da natureza de tais entidades. Ao falar das coisas tais como elas são, Espinosa se refere a substância e demais entidades da

\footnotetext{
${ }^{1}$ Doutor em Filosofia e professor da Universidade Federal de Santa Maria (UFSM), Rio Grande do Sul - Brasil. E-mail: albertinho.gallina@gmail.com
} 
mesma forma que os geômetras se referem às figuras geométricas. Desde Euclides esse processo metodológico em geometria se denomina de demonstração. Portanto, demonstrar algo é muito mais do que mostrar, é exibir de forma metódica e rigorosa o que é, seja tomado como ponto de partida, como princípio, seja como decorrência necessária dele. Portanto, tudo aquilo que pode ser dito da substância, será dito segundo demonstrações precisas e, também ocorre o mesmo com tudo o que pode ser dito como sendo dela decorrente. ${ }^{2}$ Este método, habilmente manejado por Espinosa, faz jus a velha arte dos antigos mestres da geometria.

\section{O conceito de vontade no livro I da Ética}

Nas definições da Ética I, mais precisamente na definição VI, Espinosa afirma que "Por Deus entendo ente absolutamente infinito, isto é, uma substância que consta de infinitos atributos, cada um dos quais exprime uma essência eterna e infinita". Ao que parece esta concepção de Deus está amparada numa importante mudança do conceito de substância. A explicação desta definição assomada a definição III são significativas para explicitar qual é o sentido que Espinosa atribui para a substância. Na definição III ele diz que "Por substância entendo o que existe em si e por si é concebido, isto é, aquilo cujo conceito não carece do conceito de outra coisa do qual deva ser formado" (ESPINOSA, 1983, p.76) e na explicação da definição VI ele explicita que Deus "é absolutamente infinito" mas que o mesmo não pode ser considerado como sendo "infinito no seu gênero". Estas passagens de Espinosa revelam que aqui se trata de uma concepção da substância muito distinta daquela da tradição, pelo menos da definição aceita pela tradição aristotélica.

$\mathrm{Na}$ acepção tradicional, a substância era entendida em contraposição ao acidente, ou seja, enquanto o acidente era caracterizado pela ausência de ser próprio, pois existia por outro, a substância era caracterizada como tendo ser por si mesma. Assim, a substância era um ser por si (ens per se), ao passo que o acidente era tido como aquele que existe por outro ou em outro (ens per aliud ou in alio). $\mathrm{O}$ que se depreende disto é que a definição tradicional de substância estava balizada pela questão do gênero (ens) e pela diferença específica (per se ou per aliud). Espinosa, ao contrário, quando afirma de Deus que ele "não é infinito no seu gênero" é dizer que não há gênero, ou seja, infere-se disto que a substância não é um gênero. Este afastamento em relação à definição tradicional de substância é afirmado por Marilena Chaú quando diz: "Ao afastar a definição por gênero e diferença

${ }^{2}$ A Ética de Espinosa é um estudo sobre "Deus, o homem, suas paixões e ações como se estivesse tratando de triângulos e círculos", esta é a razão pela qual ela permite "definições reais, dando-nos a conhecer, apenas pelo intelecto, suas causas e efeitos necessários, sua origem e a maneira como suas essências e existências são produzidas" (CHAUÍ, 1995, p.41). 
específica, Espinosa afasta o que a pressupõe e a sustenta: por um lado, que a substância seja o sujeito de inerência de predicados e o modo seja predicado dela, e, por outro lado, que uma definição possa operar com universais abstratos" (CHAUÍ, 1997, p.12).

Mas a revolução conceitual no que diz respeito ao conceito de substância também será estendida para outros conceitos, tais como, vontade, liberdade, ideia e tantos outros. Na primeira parte da Ética trataremos de discutir a relação entre vontade e liberdade tendo como referência a substância. Segundo a definição VII "Diz-se livre o que existe exclusivamente pela necessidade da sua natureza e por si só é determinado a agir; e dir-se-á necessário, ou mais propriamente, coagido, o que é determinado por outra coisa a existir e a operar de certa e determinada maneira (ratione)" (ESPINOSA, 1983, p.76-77). Ao dizer que a liberdade de Deus consiste em existir exclusivamente pela necessidade de sua natureza, natureza esta que inclusive determina a sua ação, a liberdade é definida em termos de uma necessidade intrínseca a própria natureza ou essência de Deus.

No apêndice do Livro I da Ética, Espinosa diz: "expliquei a natureza de Deus e respectivas propriedades, tais como: existe necessariamente; é o único; existe e age somente pela necessidade da sua natureza; é a causa livre de todas as coisas, e como é; tudo existe em Deus e dele depende de tal maneira que nada pode existir nem ser concebido sem ele; e, finalmente, que tudo foi predeterminado por Deus, não certamente por livre arbítrio, isto é, irrestrito bel-prazer, mas pela natureza absoluta de Deus, ou, por outras palavras, pelo seu poder infinito" (ESPINOSA, 1983, p.114). Aqui ele reafirma que Deus é a causa livre de todas as coisas e acrescenta que esta liberdade não pode ser confundida com o livre arbítrio, ou seja, a liberdade não consiste numa decisão livre.

Nos dois corolários da proposição XVII, que trata da ação divina, Espinosa afirma que Deus age em conformidade com a perfeição de sua natureza, sem intervenção de qualquer causa externa. Em Deus esta liberdade consiste na "única necessidade da sua natureza", agindo assim "somente pela necessidade de sua natureza", enfim, de que somente ele "é causa livre" (ESPINOSA, EI, PXVII, Cor. I e II). No escólio desta mesma proposição Espinosa procura mostrar que "o intelecto e a vontade não pertencem à natureza de Deus". Esta discussão procura estabelecer uma distinção entre ser causa livre e ter o poder de criar ou não certas coisas, tais como, "fazer com que da natureza do triângulo não resulte que os seus ângulos sejam iguais a dois retos, ou que dada uma causa não resulte o efeito" (ESPINOSA, EI, PXVII, Esc.). A crítica de Espinosa incide não somente sobre a tradição, mas também e principalmente sobre Descartes, o qual concebe um Deus voluntarista, ou, como ele mesmo afirma na Meditação Primeira, "um Deus que tudo pode". 
Ao conceber a natureza divina por analogia a natureza humana, a tradição teria confundido ambas as naturezas, donde resultou a ilusória atribuição de afetos que são próprios dos homens a Deus (cf. ESPINOSA, EI, PVIII, Esc. II) e, além disso, imaginaram como estando Deus "sujeito a paixões" (ESPINOSA, EI, PXV, Esc.). O resultado desta ilusão imaginativa não podia ser outro que ver Deus como dotado de certas faculdades, tais como, intelecto e vontade. Ora, a conseqüência desta projeção antropomórfica resultou num Deus "sumamente inteligente" que "se tivesse criado tudo o que existe no seu intelecto, nesse caso não teria podido criar nada mais, o que crêem repugnar à onipotência de Deus; e por isso preferiram admitir um Deus indiferente a tudo e não criando senão o que decretou criar por uma espécie de vontade absoluta" (ESPINOSA, EI, PXVII, Esc.). A tradição reconhece que Deus pensa coisas que nunca poderá pôr em existência. Assim, para não exaurir a potência divina e não dar margens para a imperfeição, pensam um Deus que não pode realizar tudo que está em seu poder, ou seja, acabam por retirar de Deus a própria onipotência.

Outro aspecto que mereceu uma profunda crítica por parte de Espinosa foi o fato da tradição atribuir a Deus um intelecto e uma vontade. O problema com essa atribuição resulta na suposta distinção entre o intelecto e a vontade divinos e o intelecto e a vontade humanos, disto se segue que há dois intelectos e duas vontades cuja semelhança reside somente no nome. Ora, dizer que o intelecto pertence à natureza divina e, ao mesmo tempo, aceitar uma diferença de natureza entre Deus e o homem é, em última instância, admitir que por serem radicalmente distintos, nem o nome de intelecto pode ser afirmado como sendo o mesmo. Frente a isso Espinosa aponta quatro conseqüências inevitáveis que minam a concepção daqueles a quem ele visa endereçar a sua crítica.

A primeira é que "a verdade e a essência formal das coisas são como são porque existem tais quais objetivamente no intelecto de Deus". A segunda refere-se ao intelecto divino que "enquanto é concebido como constituindo a essência de Deus, é efetivamente a causa das coisas, tanto da essência como da existência delas". A terceira parte do fato de que "como intelecto de Deus é a causa única das coisas, a saber, tanto da essência como da existência, é de necessidade que ele seja diferente das coisas, tanto em razão da essência como em razão da existência; pois o que é causado difere da respectiva causa precisamente no que dela tem". A quarta e última "por esta razão, o que é causa da essência e da existência de algum efeito deve ser diferente desse efeito, quer em razão da essência, quer na da existência" (ESPINOSA, EI, PXVII, Escólio). Conseqüentemente, admitir que Deus é a causa do nosso intelecto e de que o intelecto divino constitui a essência de Deus, é admitir uma distinção radical entre ambos os intelectos, distinção esta que nem sequer aceita que o nome seja comum. A conclusão mostra que há duas alternativas excludentes. De um lado a tradição que concebia e 
afirmava Deus como um ser transcendente, mas, que como o homem, era dotado de intelecto infinito e de vontade infinita que lhe permitia decidir e criar. Do outro lado Espinosa que, ao criticar a concepção de Deus dotado de intelecto e vontade, afirma Deus como substância única e as coisas como seus modos. A crítica ao Deus voluntarioso da tradição, que por razões desconhecidas resolveu criar o mundo e tudo que nele existe, culmina na afirmação radical de Deus como a "causa imanente de todas as coisas", conforme assevera a proposição XVIII.

Mesmo tendo tomando somente o intelecto para mostrar os equívocos do pensamento daqueles que concebem Deus como aquele que cria as coisas e, conseqüentemente, como o princípio de um processo cuja característica causal é a transitividade, Espinosa ainda reserva uma crítica à ideia da vontade livre como constituinte da essência divina, crítica apresentada a partir da proposição XXXII. O fato de que em Deus existência e essência são idênticas, de que ele é a causa eficiente da existência e da essência das coisas, e que tudo o que é determinado o é por uma causa, segue-se que: ou a vontade é causa livre, isto é, nem é causada por Deus nem por qualquer outro modo, adquirindo um certo caráter de substância; ou a vontade, enquanto modo da substância divina, é determinada a existir por outra causa. Assim, mesmo sendo concebida como vontade infinita ou finita, ela é determinada ou por Deus ou por outros modos, mas, em ambos os casos, a vontade não pode chamar-se causa livre, antes sim, "somente causa necessária ou forçosa" (ESPINOSA, EI, PXXXII, Demonstração). Espinosa conclui a Ética I afirmando que embora se possa conceber a vontade em Deus como um modo do pensar, ela jamais pode ser confundida com o livre poder de decisão, com o livre arbítrio. Assim, contrário do Deus cartesiano que, como um rei, cria os decretos livremente, o Deus de Espinosa é pura potência de ação, a liberdade nele coincide com a necessidade de causar unicamente por si todas as suas ações. A vontade, quando relacionada a Deus, nada mais é do que o poder do entendimento divino, o qual é um modo de Deus e não um atributo de sua essência.

\section{A vontade e os modos finitos no livro II da Ética}

A questão da vontade também aparece na demonstração da natureza da mente, aliás, tal qual a apresentação desta questão no livro I, aparece no final da cadeia dedutiva referente às duas partes da Ética de Espinosa. A diferença consiste em que nestes dois momentos Espinosa procura dar conta de duas diferentes perspectivas de tratamento da vontade. A primeira, como foi exposto anteriormente, quando do tratamento da substância única, dos seus atributos e modos, a crítica de Espinosa estava endereçada à concepção que atribuía a vontade a Deus que, junto com o intelecto, constituíam a natureza divina. Uma vez refutada esta posição, ainda resta uma segunda, a saber, verificar em que medida se pode conceber a mente em relação à 
vontade. A resposta de Espinosa a esta questão somente será demonstrada nas duas últimas proposições da parte II da sua Ética. Contudo, a discussão sobre a vontade somente poderá ser estabelecida a partir da explicação de Espinosa acerca da natureza da mente humana, uma vez que o que está em questão é saber em que medida a afirmação de que a vontade é uma faculdade livre da mente é verdadeira.

Das sete definições afirmadas no início da demonstração da natureza e da origem da mente consideramos que três delas são sumamente importantes para a questão proposta, a saber, a definição da relação necessária entre essência e existência; a definição de ideia como um conceito da mente; a definição da ideia adequada como a ideia que, quando considerada em si mesma, contém todas as propriedades de uma ideia verdadeira. Das definições e dos axiomas pode-se inferir que a substância age através de seus infinitos atributos infinitos em seu gênero, ou seja, de que os atributos são formas dinâmicas e ativas ou potências de ação da substância absolutamente infinita que exprimem a essência desta substância. Os modos, como expressões dos atributos, podem ser considerados como efeitos de uma causa, da ação dos atributos, e como causa de outros efeitos. Assim, à medida que o modo também é uma ação, pois é causa que produz efeitos, o modo produzido pelo atributo pensamento é uma ação de pensamento. Assim, enquanto ação, o intelecto finito age formando ideias das coisas, ou seja, se não há uma definição da mente humana, ao menos pode ser estabelecida uma propriedade ou característica da mente, qual seja, a mente consiste em formar ideias das coisas. O que parece estar em conformidade com a definição que afirma ser a ideia um conceito da mente.

A proposição III trata da existência necessária em Deus da ideia da sua essência e da modificação imediata e infinita da mesma, isto é, de que a potência de Deus consiste no desdobramento da sua essência, segue-se disto que Deus pode formar a ideia de sua essência e de sua potência ("de tudo o que necessariamente se segue da sua essência"). Aqui há duas importantes questões interligadas, a saber, a potência e a sua ideia ou a potência e a ciência de Deus. Quanto à primeira Espinosa afirma um poder atual e não mais virtual, conforme se apresenta na tradição através da dupla conceitual potência e ato, a saber, ao identificar potência e ato, Espinosa identifica aquilo que é ou que existe necessariamente com o conhecimento ou a ciência disto que é. Em outros termos, a ideia é imanente ao ser de Deus, esta identidade entre o ser e o conhecer é o que faz de Deus uma potência atual, uma coisa pensante. Assim, a ideia de Deus é o conhecimento de tudo aquilo que se segue dele por necessidade. Esta proposição indica que pertence à natureza de Deus compreender-se e agir, isto é, de que a partir da modificação ou do desdobramento, tudo que se segue da essência é concebível ou inteligível.

Mas o escólio desta mesma proposição retoma a discussão da parte I da Ética. Nele Espinosa reafirma o preconceito do homem vulgar em 
associar a potência divina ao livre arbítrio e, como conseqüência, admitir a contingência das coisas existentes. Pelo que foi anteriormente dito, acerca do que está proposto aqui, a afirmação de que "Deus age em virtude da mesma necessidade pela qual se compreende a si mesmo" (ESPINOSA, EII, PIII, Escólio), conforme a demonstração da proposição XVI da parte I, Espinosa estabelece que a ação divina não se dá voluntariamente, isto é, por uma decisão, tampouco se dá em função do intelecto. A conseqüência desta proposição, reafirmada pelo escólio, constitui uma crítica contundente as concepções filosóficas tanto da tradição, quanto dos seus contemporâneos. Com a identificação da ciência e da potência de Deus, Espinosa estabelece um distanciamento e uma superação das teorias que se baseiam na possibilidade, na contingência, na criação, pois, uma vez que a ação e a ciência de Deus não têm como ponto de partida a vontade ou o intelecto, a existência das coisas não é produto de uma ação contingente. Tanto a teoria cartesiana da criação das coisas e das verdades eternas, quanto a teoria leibniziana dos mundos possíveis, parecem estar submetidas a esta crítica por parte de Espinosa. ${ }^{3}$

A proposição IV coloca a base para a constituição de uma ciência única, ou seja, ao afirmar que "a ideia de Deus, da qual se seguem coisas infinitas em infinitos modos, não pode ser senão única" ESPINOSA, EII, PIV), Espinosa está afirmando que o que constitui a ideia de Deus é a ideia de uma substância única, constituída por atributos e modos. Posto deste modo se pode dizer que a ideia de Deus é a ideia deste princípio imanente e necessário do qual tudo se segue, princípio que é interno ao processo causal. Disto segue-se, conforme é afirmado na proposição $\mathrm{V}$, que "o ser formal das ideias reconhece Deus por causa apenas enquanto ele é considerado como coisa pensante, e não enquanto ele se explica por um outro atributo" ESPINOSA, EII, PV). Ao que parece são as ideias, enquanto seres reais, enquanto explicações (desdobramentos) do atributo pensamento, e não como representações ou imagens de coisas, que reconhecem enquanto causa não os objetos percebidos, "mas o próprio Deus, na medida em que ele é uma coisa pensante". Este "na medida em que ele é" indica que o reconhecimento de que fala Espinosa tem a ver com a substância e a ação de um de seus atributos, a saber, o atributo pensamento. Como esta proposição traz alguns embaraços no tocante ao seu entendimento, convém uma análise mais detalhada.

Em primeiro lugar, convém notar que Espinosa afirma que Deus é coisa pensante porque o atributo pensamento constitui a sua essência. Ao nomeá-lo como coisa pensante, Espinosa não quis dizer que o que está em questão é se Deus pode ou não pensar, mas que o pensamento constitui a sua essência. Em segundo lugar, devemos considerar que a causa de uma ideia não é o ideado ou a coisa ideada, como queria a tradição realista escolástica,

${ }^{3}$ Esse problema não será abordado neste artigo. 
e tampouco a mente humana como substância pensante criada. A causa de uma ideia é a mente humana enquanto modo do atributo pensamento. Disso se segue que a mente é a ideia porque é modo do pensamento, ou seja, a mente forma ideias porque é modo do pensamento.

Há uma distinção entre os conceitos "exprimir" e "explicar" que permite elucidar essas questões. Na versão francesa de Charles Appuhn há duas passagens onde estas expressões aparecem e, em ambas as passagens, elas estão relacionadas com o conceito "atributo". $\mathrm{Na}$ proposição V, Espinosa diz que o reconhecimento de Deus como causa não se dá "en tant qu'il s'explique par un autre attribut" (SPINOZA, 1965, p.74, grifo nosso), ao passo que na demonstração desta mesma proposição é dito "l'être formel des idées est un mode du penser (comme il est connu de soi), c'est-à-dire un mode qui exprime d'une certaine manière la nature de Dieu en tant qu'il est chose pensante, et ainsi n'enveloppe le concept d'aucun autre attribut de Dieu” (SPINOZA, 1965, p.74, grifo nosso). Já no escólio da proposição VII, Espinosa diz em momentos diferentes que "De même aussi un mode de l'étendue et l'idée de ce mode, c'est une seule et même chose, mais exprimée en deux manières" e mais adiante afirma que "un cercle existant dans la Nature et lidée du cercle existant, laquelle est aussi en Dieu, c'est une seule et même chose qui s'explique par le moyen d'attributs différents" (SPINOZA, 1965, p.76, grifo nosso). Nas passagens acima os verbos "explicar" e "exprimir" parecem dizer coisas diferentes. Diferença essa que parece ter escapado na versão para o português.

Quando Espinosa utiliza o verbo na voz ativa "exprime" ou na voz passiva "exprimée", ele está se referindo à ação dos atributos que se exprimem mediante uma infinitude de modos. O acento recai sobre os atributos que, por serem distintos entre si, agem produzindo distintos modos como seus efeitos. Parece que ao usar o verbo exprimir Espinosa está se referindo à ação pela qual os infinitos atributos produzem infinitas ordens, produção esta que é a expressão referida à substância única. Entretanto, nas duas passagens onde Espinosa diz "s'explique", referindo-se a Deus, a ideia do círculo e ao círculo existente na natureza, ele utiliza o verbo explicar para denotar uma ação dos atributos na qual está envolvido o modo enquanto um ser, seja o ser da ideia de Deus ou da ideia do círculo ou o ser do círculo existente na natureza. Ao que parece o acento aqui recai sobre o conceito de modo, seja efeito do pensamento ou da extensão, enquanto atributos divinos. Explicar significa desdobrar-se, um desenvolver-se de Deus, enquanto res cogitans no caso das ideias de Deus e do círculo e, enquanto res extensa no caso do círculo existente na natureza.

$\mathrm{O}$ que se pode inferir da proposição $\mathrm{V}$ é que o reconhecimento de Deus como causa eficiente somente é possível pelo fato de que Deus se explica através do atributo pensamento, e se explica enquanto causa eficiente do ser formal das ideias. Mas se Deus é a causa eficiente e se os atributos são potências de ação, então as ideias são a efetividade desta ação 
e, segue-se disto, pela relação de imanência entre os modos e a substância, que as ideias só podem ser ações. Caso contrário, haveria uma transcendência entre a causa das ideias e as ideias mesmas, ou seja, o processo causal seria caracterizado pela transitividade entre a causa e o efeito e, ao que parece, Espinosa não admitiria este tipo de relação causal.

Mesmo que os modos sejam produzidos por seus atributos, esta produção não significa atribuir uma característica de substância aos atributos, pois se assim fosse, recairíamos no problema de conceber várias substâncias ao invés da substância única. A proposição VI permite compreender melhor esta questão, nela é afirmado que "os modos de cada atributo têm por causa Deus apenas enquanto ele é considerado sob o atributo de que eles são modos, e não enquanto é considerado sob outro atributo" (ESPINOSA, EII, PVI). Aqui é afirmado que os modos têm por causa Deus, mas que estes modos são causados segundo a diversidade dos atributos, ou seja, os modos são causados por Deus sob um atributo e afirmam a diversidade devido a autonomia de cada atributo. Isto permite dizer que os modos, em suas conexões, formam ordens diferentes segundo os diferentes atributos "de que eles são modos".

No corolário desta mesma proposição é afirmado que "daí se segue que o ser formal das coisas, que não são modos do pensamento, não resulta da natureza divina pelo fato de que ela conheceu primeiro as coisas" (ESPINOSA, EII, PVI, Corolário), isto indica que o ser formal das coisas não é produto de um intelecto que contempla as ideias destas coisas e de uma vontade que as criou. Ou, como afirma Gueroult, "Deus não produz as coisas a partir das ideias ou dos arquétipos que ele teria antes das coisas, mas ele produz simultaneamente as coisas e as ideias das coisas a partir dos atributos que lhes são próprios" (GUEROULT, 1974, p.61).

$\mathrm{Na}$ sequência do corolário é afirmado que "as coisas ideadas seguem-se e deduzem-se dos seus respectivos atributos da mesma maneira e com a mesma necessidade que demonstramos que as ideias se seguem do atributo pensamento" (ESPINOSA, EII, PVI, Corolário). O que está em questão é que da mesma maneira como as ideias conectam-se no pensamento, as coisas ideadas conectam-se em seus respectivos atributos. Mas se de fato é assim, como as coisas que se seguem de outros atributos, que não o pensamento, podem ser ditas "coisas ideadas" ou coisas que podem ser pensadas? Antes de verificar como este problema é resolvido, convém notar que a discussão proposta no corolário permite entrever como a questão da vontade, apresentada no final desta parte da Ética, está de alguma forma relacionada com a concepção que Espinosa tem da ideia.

A demonstração da proposição VII, onde é afirmada que "a ordem e a conexão das ideias é a mesma que a ordem e a conexão das coisas", faz menção ao axioma 4 da Parte I, a saber, "o conhecimento do efeito depende do conhecimento da causa e envolve-o". Uma leitura desatenta destas duas afirmações poderia sugerir que o conhecimento se dá segundo uma relação 
entre a ideia e o objeto que a causa, entretanto, esta relação causal externa já foi vedada nas proposições anteriores. Daí se segue que o conhecimento afirmado no axioma 4 se refere ao "conhecimento da causa de que ela (ideia) é o efeito" (ESPINOSA, EII, PVII, Demonstração). Assim, a relação causal de que trata Espinosa é a relação causal ao nível das ideias. Mas como entender isto? Gueroult sugere que o que está sendo tratado nesta proposição diz respeito, seguindo a afirmação da autonomia dos atributos, as ideias que, enquanto coisas, causam-se umas às outras, ou seja, as ideias são causas umas das outras (cf. GUEROULT, 1974, p.67).

Segundo a afirmação de que a potência de pensar é igual à potência de agir, e pela afirmação da autonomia dos atributos, resulta que o conhecimento das ideias é, em última instância, conhecimento da ordem e da conexão interna ao próprio atributo pensamento, ou seja, conhecimento das causas destas ideias, causas estas que são as ideias enquanto coisas ou o ser formal das ideias. Pois como modos do pensamento "as ideias são concebidas como coisas que se causam umas as outras, segundo a ordem e a conexão de sua causalidade no atributo pensamento. Mas como a ordem e a conexão das ideias é a mesma coisa que a ordem e a conexão das causas ou das coisas, então, a ordem e a conexão das ideias são a mesma coisa que a ordem e a conexão das causas ou das coisas no atributo pensamento" (GUEROULT, 1974, p.67). Disto se segue que a proposição VII trata de uma simultaneidade entre a ordem e a conexão que ocorre no interior do atributo pensamento, a saber, a ordem e conexão das ideias são as mesmas que a ordem e conexão das causas das ideias, como a causa destas ideias não pode ser as coisas exteriores ao atributo pensamento, então, as causas das ideias são as próprias ideias enquanto coisas.

Mas convém observar que no corolário da mesma proposição Espinosa diz que "a potência de pensar de Deus é igual à sua potência atual de agir. Isso é, tudo o que se segue formalmente da natureza infinita de Deus segue-se também em Deus objetivamente na mesma ordem e com a mesma conexão da ideia de Deus" (ESPINOSA, EII, PVII, Corolário). Disto se depreende que a ordem e a conexão também indicam uma simultaneidade que se estabelece ao nível da relação entre os infinitos modos dos infinitos atributos, uma vez que os infinitos modos dos infinitos atributos são efeitos de uma mesma causa, a saber, da substância única, pois as modificações produzidas nos diferentes atributos são expressões de uma mesma substância.

No escólio está afirmação é reforçada por outra, a saber, "da mesma maneira, também um modo da extensão e a ideia desse modo são uma e a mesma coisa, mas expressa de duas maneiras diferentes", isto é, "quer concebamos a Natureza sob o atributo da extensão, quer sob o atributo do pensamento, quer sob outro atributo qualquer, encontraremos sempre uma só e a mesma ordem, por outras palavras, uma só e a mesma conexão de causas, isto é, encontraremos sempre as mesmas coisas seguindo-se uma das 
outras" (ESPINOSA, EII, PVII, Escólio). Esta ideia de uma infinita cadeia causal ratifica a definição VI da parte I onde Espinosa afirma: "Por Deus entendo o ser absolutamente infinito, isto é, uma substância que consta de infinitos atributos, cada um dos quais exprime uma essência eterna e infinita”. Deus é uma substância constituída por infinitos atributos infinitos em seu gênero, Deus é esta diversidade real dos atributos e dos modos, mas uma diversidade onde a ordem e a conexão exprimem o absoluto.

Do que foi dito anteriormente sobre a ordem e a conexão que ocorre no interior do atributo pensamento, resulta que a ideia é entendida sob dois aspectos diferentes, a saber, por um lado temos a essência formal da ideia, o seu ser formal, que é a ideia enquanto uma ação causal e, por outro, temos a essência objetiva da ideia, o seu ser objetivo, que é a ideia enquanto efeito desta ação ou a ideia enquanto o conceito de uma coisa ideada. Disto resulta que o conhecimento é o saber que a ideia tem de si mesma enquanto ideia, a ideia da ideia, um conhecimento cuja base epistêmica está calcada na ideia tendo como referência à própria ideia, ou seja, o conhecimento da ideia, como essência objetiva, é o conhecimento da ordem e da conexão das ideias, como essências formais, que causam aquela ideia.

Esta questão também é tratada na proposição XXI, mais precisamente no seu escólio, quando é dito "Com efeito, na realidade, a ideia da mente, isto é, a ideia da ideia, não é senão a forma da ideia, enquanto considerada como um modo de pensar sem relação com o objeto. Efetivamente, ao mesmo tempo em que alguém sabe alguma coisa, sabe, por isso mesmo, que sabe, e, ao mesmo tempo, sabe que sabe o que sabe, e assim até o infinito" (ESPINOSA, EII, PXXI, Escólio). Segundo este escólio a ideia da ideia é a forma da ideia, portanto, se considerarmos a ideia como saber, segue-se que a ideia da ideia é o saber do saber ou, conforme o texto, o saber "que sabe o que sabe". Mas destas três características da ideia, quais sejam, a essência objetiva, a essência formal e a ideia da ideia, não se pode concluir que no atributo pensamento encontram-se três realidades distintas, antes sim que são apenas distinções de razão, ou seja, três aspectos de uma mesma realidade modal (cf. GUEROULT, 1974, p.70).

Assim como as outras realidades modais dos outros atributos são ações da substância, pode-se dizer que as ideias, enquanto realidades modais do atributo pensamento, são também ações da substância e, consequentemente, que as ideias são atos do pensamento. Esta conseqüência se ergue contra a teoria cartesiana das ideias como imagens. Desta discussão também se pode concluir que a causa do ser das ideias não é os ideados, mas que Deus é a causa das ideias ou da sua realidade. A conclusão é deveras importante, uma vez que as ideias não são representações cuja causa de alguma forma transcende a própria ideia, seja Deus enquanto um ideado ou uma existência qualquer, segue-se que para Espinosa as ideias são ações ou atos. Afirmar a ideia enquanto ação, é afirmar uma concepção de ideia diametralmente oposta a concepção cartesiana, qual seja, da ideia enquanto 
uma imagem, uma pintura ou, como a tradição denomina, representação. Ora, pensar a ideia como imagem, é pensá-la como uma "pintura muda", como algo passivo. Disto se segue que esta noção de ideia tal como Espinosa estabelece na Ética, como ato, permite vislumbrar a discussão e a divergência dele com Descartes no tocante à vontade.

Para Descartes a vontade consiste numa faculdade da mente, faculdade esta que se caracteriza pela liberdade absoluta. A vontade para Descartes é a faculdade que torna possível os juízos mediante a afirmação ou a negação quando da composição de duas ou mais ideias. Mesmo tendo duas concepções distintas sobre a vontade, uma nas Regras e outra nas Meditações, a concepção que prevalece é a da vontade como um poder imprescindível para o estabelecimento da ciência. Este poder atribuído a vontade se dá devido à concepção cartesiana da ideia como representação. No escólio da proposição XLVIII Espinosa se refere à definição III, procurando desfazer a crença de que a mente é causa livre ou um sujeito de ações voluntariamente decididas das quais as ideias seriam os efeitos. Para tal se apoia na proposição XI, em que demonstrou que a mente é uma ideia e, como ideia, age em relação às ideias que ela produz.

Caracterizando a ideia como atividade, Espinosa afirma que a ideia não é uma percepção da mente, que a mente não padece diante do objeto. Ao dizer que a ideia não se forma a partir da mente, ou na mente, diz que a ideia não se forma a partir do objeto do qual ela é uma representação, mas de modo completamente autônomo, por sua dinâmica própria de ideia. Ou seja, ao afirmar que "a ideia enquanto ideia (idea quatenus idea est), permanece no interior da realidade substancial do pensamento" (ESPINOSA, EII, PXLVIII, Escólio), Espinosa quer nos indicar que a atividade da ideia é aquela que lhe é comunicada pelo próprio pensamento.

A investida de Espinosa contra Descartes no tocante à vontade como faculdade livre é feita de forma sistemática: "Na mente não existe vontade absoluta ou livre; mas a mente é determinada a querer isto ou aquilo por uma causa que também é determinada por outra, e essa outra, por sua vez, por outra, e assim até ao infinito" (ESPINOSA, EII, PXLVIII). Esta afirmação pressupõe a concepção da mente como ideia do corpo e como tal, diz Espinosa, "é um certo e determinado modo de pensar", ou seja, a mente é um modo do pensamento e não uma substância pensante, como queria Descartes.

Por causa livre Espinosa entende a própria essência da coisa para agir, e por vontade livre entende a faculdade absoluta de querer e não querer. Sendo assim, Espinosa afirma a ideia da causa livre e critica ideia de uma vontade. Por livre, Espinosa entende a ação que se segue necessariamente da própria essência da coisa, isto é, essência e potência são idênticas. Por vontade entende o ato de escolher entre possíveis contrários. $O$ que Espinosa de fato recusa é a ideia de uma potência de autodeterminação para a ação, não obstante afirme a ideia de uma potência 
de autodeterminação que age pela necessidade da própria essência. Sendo assim, toda volição é determinada por uma causa e não pode haver uma vontade livre como "faculdade absoluta de querer ou de não querer" (ESPINOSA, EII, PXLVIII, Demonstração). No escólio da mesma proposição Espinosa dá a entender que a não existência da vontade enquanto uma faculdade absoluta, como também das "faculdades absolutas de entender, de desejar, de amar, etc.", consideradas como "entes metafísicos" ou "universais", não implica a não existência de volições particulares.

Após distinguir a vontade, enquanto faculdade de afirmar ou negar o que é verdadeiro e o que é falso, do desejo que apetece a mente, ele aponta para uma questão decisiva, a saber, a necessidade de investigar "se existe, na mente, outra afirmação ou outra negação além daquela que envolve a ideia, enquanto ela é uma ideia" (ESPINOSA, EII, PXLVIII, Escólio). Espinosa distingue a vontade do desejo e a ela se refere como sendo afirmação e negação. $\mathrm{O}$ querer e o não querer são desejos e, como tais, distintos do afirmar e do negar. A crítica de Espinosa incide sobre a ideia de uma vontade que se identifica com os desejos, pois, sendo a realidade uma sequiência de causas necessárias e infinitas, numa tal cadeia de determinações, carece de sentido falar em vontade absoluta, sequer faz sentido falar em querer ou não querer.

Além disto a distinção entre desejo e vontade serve para apontar uma identidade entre vontade e inteligência e, ambas, enquanto "volições e ideias singulares" e estas como "uma só e mesma coisa" (ESPINOSA, EII, PXLIX, Demonstração do corolário). Disto se segue que a distinção acima referida não só estabelece que a vontade, enquanto volição é uma ideia singular, ou seja, a vontade é de natureza estritamente mental, mas que a vontade participa da própria ideia. Uma vez redefinida a vontade em contraposição ao desejo, e ter identificado a vontade com a ideia, Espinosa pode afirmar que "na mente não existe nenhuma volição, isto é, nenhuma afirmação e nenhuma negação, além da que envolve a ideia, enquanto é uma ideia" (ESPINOSA, EII, PXLIX). A vontade só existe na ideia, ou seja, é uma propriedade da ideia, enquanto é afirmação da ideia por si mesma.

Com isso podemos dizer que o conceito de ideia é fundamental para a compreensão do conceito de vontade, pois este de um novo significado atribuído àquele. Por ser a vontade distinta do desejo e a afirmação uma propriedade da ideia, uma espécie de força de autoafirmação interna, resulta que a ideia, considerada em si mesma, sempre envolve uma afirmação. Portanto, para Espinosa aquilo que constitui a mente não são percepções passivas de objetos, mas asserções de conteúdos proposicionais, as quais ele denomina por ideias. Jamais podemos pensar em uma ideia sem que uma asserção acompanhasse esse pensamento. Posto nestes termos, toda ideia é um ato judicativo, na qual uma proposição é pensada e uma verdade asserida, ou, pensar seria idêntico a fazer juízos. Neste preciso sentido pensa Espinosa ter refutado a tese cartesiana de uma faculdade livre, uma vez que 
esta somente tem sentido quando subordinada a outra tese cartesiana que afirma haver uma distinção entre as faculdades de perceber e de querer. Esse esclarecimento inicial sobre o conceito de vontade, a partir do conceito de ideia, será importante para entendermos como Espinosa se afasta da tradição no tocante a relação entre vontade e conhecimento e vontade e liberdade.

\section{Vontade, juízo e a questão do conhecimento}

Em Descartes a vontade incide sobre o juízo, que é composto de ideias, mas não é de forma alguma uma propriedade da ideia. A ideia enquanto representação ou imagem não envolve nenhuma asserção, quer seja de afirmação ou negação. No contexto da filosofia cartesiana vontade e livre arbítrio são a mesma coisa, uma vez que a vontade que afirma ou nega é a mesma vontade que quer ou não quer, pois todas estas ações são ações da vontade. Espinosa afirma que a vontade é distinta do desejo e de que como afirmação ou negação ela está relacionada com a ideia, ou seja, caracteriza-se como uma força de auto-afirmação interna a própria ideia. $\mathrm{O}$ restabelecimento do sentido positivo da vontade advém do fato de que a ideia, considerada em si mesma, sempre envolve uma afirmação. Ao utilizar os exemplos das ideias imaginativas, como a do cavalo alado, ele mostra que esta capacidade de afirmação da ideia independe da adequação ou não do seu conhecimento. Por exemplo, a ideia como a de um cavalo alado, possui em si mesma uma capacidade de afirmação, a qual independe da adequação ou não do seu conhecimento. Ao identificar a afirmação como pertencente à natureza da ideia, Espinosa redefine o critério de verdade por exclusão de uma passagem ao exterior da ideia.

A diferença de Espinosa para com Descartes aqui é significativa. Descartes pensava que a afirmação era uma ação da vontade e que esta era exterior à ideia, daí ser o juízo uma ação da vontade resultante da afirmação exercida sobre a ideia. Resulta desta concepção que a verdade e o erro são produtos de uma má aplicação da ação da vontade, donde se segue que o valor de verdade, isto é, aquilo que torna possível o verdadeiro e o falso, aparece como extrínseco à ideia. Desta exterioridade da vontade em relação à ideia resulta que o conhecimento, quer seja verdadeiro, quer seja falso, depende de uma ação externa a ideia ela mesma. Ao identificar a afirmação e a negação como pertencentes à natureza da ideia, Espinosa redefine a noção de verdade e de falsidade. Mas se as ideias em si mesmas são todas dotadas de afirmação, o que as torna diferentes e permite identificar uma ideia puramente intelectual de uma ideia imaginativa?

No escólio da proposição XLIX Espinosa aponta para duas situações em que a afirmação não ocorre. A primeira está relacionada com a presença de uma outra ideia que suprime a existência da ideia em questão; a segunda ocorre quando a mente percebe que a ideia que tem é inadequada. Ao que parece, a ausência de afirmação das ideias nestes dois casos não está no 
mesmo nível daquele primeiro, a saber, a da afirmação da ideia enquanto considerada em si mesma. Estes casos onde a afirmação está ausente estão diretamente relacionados com o conhecimento da ideia e não com a ideia propriamente dita. Mais adiante, no mesmo escólio, Espinosa diz que a afirmação existe em todas as ideias "mas não enquanto é considerada como constituindo a essência da ideia, pois, nesse ponto de vista, as afirmações diferem entre si, tanto como as próprias ideias" (ESPINOSA, EII, PXLIX, Escólio). Quando a ideia é adequada, segue-se necessariamente sua afirmação, mas quando a ideia é considerada junto com outra ideia que suprime sua existência ou quando uma ideia é percebida pela mente como inadequada, segue-se necessariamente sua negação.

Sendo assim, a existência da afirmação em relação à essência da ideia é o que se denomina de verdade e a sua ausência é a falsidade. Desta relação, conclui Espinosa, "com efeito, essas duas afirmações, se considerais a mente, estão entre si na mesma relação que o ser e o não-ser, nada existindo nas ideias de positivo que constitua a forma da falsidade" (ESPINOSA, EII, PXLIX, Escólio). Para Espinosa a ideia falsa é corrigida pela ideia verdadeira. A ideia imaginativa do sol desaparece dando lugar a imagem do sol que permanece compreendida pela adequada ideia do sol. Assim, conforme assinala a proposição XXXV, "com efeito, embora, mais tarde, venhamos a saber que o sol se encontra afastado de nós mais de seiscentas vezes o diâmetro da Terra, não deixaremos, todavia, de imaginar que ele está perto de nós" (ESPINOSA, EII, PXXXV, Escólio).

Para Espinosa, o critério de verdade não é o critério da correspondência da ideia com o ideado, uma vez que, conforme a discussão da proposição VII da parte II, se há um critério este critério deverá ser interno a própria ideia e não mais externo. A afirmação da verdade não implica relações causais externas à própria ideia, pois, "ao demonstrar que uma ideia verdadeira é aquela que apresenta a gênese necessária de seu objeto, oferecendo as causas necessárias de sua essência, Espinosa já não precisa de critérios exteriores que garantam a veracidade de uma ideia", isto é, por ser a verdade um "index sui” ou um "índice de si mesma”, é que "a ideia verdadeira é aquela que mostra as operações realizadas pelo intelecto para concebê-la, construindo o objeto (o ideado, ou conteúdo da ideia) através de suas causas necessárias" (CHAUÍ, 1995, p.43). Como a afirmação da verdade não exige passagem ao exterior, a ideia verdadeira é "a que apresentar-se a si mesma como conhecimento da gênese necessária de seu objeto" (CHAUÍ, 1995, p.43). Este critério de verdade, somado à redefinição do conceito de ideia e do conceito de vontade, permite a Espinosa não só realizar uma crítica ao modelo epistêmico cartesiano, baseado na representação e na correspondência, mas, sobretudo, afirma o conhecimento como processo de busca e afirmação das causas.

\section{Vontade, ação e a questão da liberdade}


A identificação entre o pensar e a atividade judicativa permitiu a Espinosa estabelecer a distinção entre o perceber e o querer e, com ela, refutar a tese cartesiana de uma faculdade livre. Contudo, ainda resta saber em que medida a sua concepção da ideia nos auxilia para pensarmos a relação entre vontade e liberdade.

A passagem para a ação se dá pelas noções comuns, umas menos e outras mais universais. Na proposição XXXIX Espinosa demonstra que o que é comum ao meu corpo e a certos corpos exteriores o é igualmente em cada um desses corpos. Esta ideia é dada na substância infinita, não apenas enquanto ela tem ideia dos corpos exteriores, mas também enquanto ela tem a ideia de meu corpo, pois essa é uma das condições para se ter à ideia disso que é comum a ambos (ESPINOSA, EII, PXXXIX). Também demonstra que há outras noções mais universais, por exemplo, daquilo que é comum a todas as coisas e o é igualmente na parte e no todo, a ideia disso também ela é dada na substância (ESPINOSA, EII, PXXXVIII). Essas demonstrações fundam os dois aspectos sob os quais as noções comuns em geral são necessariamente adequadas.

As noções comuns são ideias que se explicam formalmente por nossa potência de pensar e que, materialmente, exprimem a ideia da substância como sua causa eficiente. Noutros termos, elas exprimem a substância como causa porque, dado que a substância as possui como nós as possuímos, elas envolvem necessariamente a essência eterna e infinita da substância (ESPINOSA, EII, PXLV e Escólio). Entre as ideias que temos, as únicas que podem expressar a essência da substância, ou envolver o conhecimento desta essência, são as ideias que estão em nós como na substância, a saber, as noções comuns (ESPINOSA, EII, PXLVI).

A questão é como se pode chegar a tais ideias adequadas visto que não temos ideias de nós mesmos, nem dos corpos exteriores, mas somente ideias de afecções indicando o efeito de um corpo exterior sobre nós. Ora, para Espinosa é precisamente a partir deste efeito que podemos formar a ideia do que é comum a um corpo exterior e ao nosso. E esta é a única via que nos conduz a uma ideia adequada. A primeira ideia adequada que temos é a noção comum, a ideia de alguma coisa em comum. Esta ideia se explica por nossa potência de compreender ou pensar. A potência de compreender é a potência de pensar da mente. Portanto, somos ativos enquanto formamos noções comuns.

A noção comum marca o momento em que estamos de posse formal de nossa potência de agir, constituindo o segundo momento da razão, que em sua gênese é o esforço de organizar encontros em função das conveniências e inconveniências percebidas. A razão, na sua atividade, é o esforço em formar noções comuns, compreender intelectualmente conveniências e inconveniências. Quando formamos uma noção comum, nossa mente se serve da razão, nos tornamos racionais. Uma noção comum é 
nossa primeira ideia adequada. Mas qualquer que ela seja, ela nos leva imediatamente à outra ideia adequada que, por sua vez, exprime a essência eterna e infinita da substância.

A ética começa na passagem da paixão à ação mediante um processo de reflexão, isto é, num processo no qual a mente humana se torna apta a encadear por si mesma as ideias das afecções corporais e apta a compreender que a causa dessas afecções é o próprio corpo na relação com outros e que a causa das ideias é a própria mente. Por isso Espinosa demonstra que "um afeto que é paixão deixa de ser paixão quando dele formamos uma ideia clara e distinta". O afeto deixa de ser uma paixão para se tornar um afeto que em relação ao corpo produz desejos e em relação a mente produz ideias. Pois também em relação a mente é um afeto fundamental que desencadeia a ação de pensar, isto se dá quando a mente, enquanto ideia do corpo, descobre por reflexão a sua própria essência. A este afeto fundamental no qual tem origem a ação de pensar Espinosa atribui o nome de "a ideia da ideia".

Embora se possa conceber a vontade como um modo do pensar, ela jamais pode ser confundida com o livre poder de decisão, com o livre arbítrio, pois a vontade não é uma faculdade é somente uma propriedade da ideia. Ademais aquilo que é determinado, é determinado pela essência do corpo e pela essência da mente. Donde se segue que a liberdade para Espinosa não pode ser entendida no sentido de um poder da vontade, nem para se posicionar frente alternativas, sequer para purificar os pensamentos das afecções causadas pelo corpo.

No primeiro livro da sua Ética, Espinosa afirma que "livre é o que existe exclusivamente pela necessidade da sua natureza, e por si só é determinado a agir; e dir-se-á necessário, ou mais propriamente, coagido, o que é determinado por outra coisa a existir e a operar de certa e determinada maneira" (ESPINOSA, EI, DVII). Ao dizer que a liberdade consiste em existir exclusivamente pela necessidade de sua natureza, natureza esta que determina a sua ação, Espinosa assinala que a liberdade somente pode ser definida em termos de uma necessidade intrínseca à natureza ou essência da substância. Na proposição XVII é afirmado que no caso da substância infinita, a liberdade consiste na "única necessidade da sua natureza", e de que uma tal substância age "somente pela necessidade de sua natureza". A tese defendida por Espinosa no Livro I é de que existir e agir pela necessidade da natureza é ser a causa livre de todas as demais coisas. Isso significa que, se a liberdade coincide com a necessidade, então a fonte de todas as coisas não é a sua causa transcendente, mas sim uma causa imanente. Sendo assim, em que consiste a liberdade para Espinosa?

Porque ser livre para Espinosa é se conhecer como sendo a causa dos desejos e das ideias. Como essa causa também é ela causada pelos afetos, a liberdade não pode ser confundida com o livre arbítrio, e sequer ser confundida com uma escolha. Dado que para Espinosa o conhecimento é um 
processo no qual a mente descobre as causas dos apetites e dos desejos, processo este no qual a mente não só compreende a ideia do corpo, mas também se compreende a si mesma como ideia da ideia do corpo. Portanto, ser livre é ter o conhecimento de si mesmo como integrante desse processo causal imanente que constitui a substancia infinita. 


\section{Referências bibliográficas}

CAHIERS SPINOZA (2 e 5). Paris: Éditions Réplique, 1985.

CHAUÍ, Marilena. Espinosa: uma filosofia da liberdade. São Paulo: Editora Moderna, 1995.

. Espinosa e a Essência Singular. Texto apresentado no II Encontro de Estudos do Século XVII, 1997. (Mimeo)

. A Nervura do Real: Imanência e Liberdade em Espinosa. São Paulo:

Companhia das Letras, 1999.

DESCARTES, René. Meditações. 3. ed. São Paulo: Abril Cultural, 1983.

. Regras para a Direção do Espírito. Lisboa: Edições 70, 1985.

ESPINOSA, Baruch de. Ética. 3. ed. São Paulo: Abril Cultural, 1983.

GUEROULT, Martial. Spinoza II - L'Âme (Ethique, II). Paris: AubierMontaigne, 1974.

SPINOZA. Éthique. Paris: GF Flammarion, 1965.

SPINOZA. Correspondencia. Madrid: Alianza Editorial, 1988. 